\title{
Non-Stick Coatings in Aluminium Molds for the Production of Polyurethane Foam
}

\author{
Francisco Sánchez-Urbano ${ }^{1}$, Guillermo Paz-Gómez ${ }^{2}$, Óscar Rodríguez-Alabanda ${ }^{1}$ (1) , \\ Pablo E. Romero ${ }^{1, *(1)}$, Miguel Cabrerizo-Vílchez ${ }^{2}$, Miguel Ángel Rodríguez-Valverde ${ }^{2}$ and \\ Guillermo Guerrero-Vaca ${ }^{1}$ (i) \\ 1 Department of Mechanical Engineering, University of Cordoba, Medina Azahara Avenue 5, 14071 Cordoba, \\ Spain; franurbano94@icloud.com (F.S.-U.); orodriguez@uco.es (O.R.-A.); \\ guillermo.guerrero@uco.es (G.G.-V.) \\ 2 Biocolloid and Fluid Physics Group, Applied Physics Department, Faculty of Sciences, \\ University of Granada, Campus de Fuentenueva s/n, 18071 Granada, Spain; gpaz@ugr.es (G.P.-G.); \\ mcabre@ugr.es (M.C.-V.); marodri@ugr.es (M.Á.R.-V.) \\ * Correspondence: p62rocap@uco.es; Tel.: +34-957-212-235
}

Received: 17 July 2018; Accepted: 24 August 2018; Published: 27 August 2018

\begin{abstract}
The manufacturing of polyurethane foam is a process of great industrial importance in the automotive and furniture sector. The operation of demolding is the most delicate, since the foam sticks firmly to the walls of the mold onto which it has spread. In order to avoid the use of demolding agents, the proposal is to coat the inside of the molds with non-stick coatings. In this work, three types of different coatings were studied: fluoropolymers, ceramics, and elastomers. After carrying out different tests in the laboratory, two fluoropolymer coatings (PFA (perfluoroalkoxy) and PTFE (polytetrafluoroethylene)) were selected for a test at the industrial level and, after 1500 cycles of demolding, it was experimentally proven that the PFA coating is the most adequate for the use studied.
\end{abstract}

Keywords: non-stick coatings; polyurethane foam; aluminium molds; FEP; PFA; RTV silicone rubber; sol-gel

\section{Introduction}

The polyurethanes (PURs) include an extensive group of polymers with an enormous range of compositions and properties, with applications such as adhesives, elastomers, coatings, and foam [1,2]. The main areas of applied usage of polyurethane foam are those that require absorption and padding. Flexible uses of polyurethane foam include: cushions used in car seats and in furniture, floor coverings and carpets, mattresses, pillows, and household appliances, among others [3,4].

The production of polyurethane foam is accomplished by polycondensation of polyisocyanates with polyols $[5,6]$. The mixture of the aforementioned components in their respective adequate proportions, and after having been removed from the mold, generates a reaction that produces a gas and the formation of foam. Following this step, the molded piece and foam are removed and allowed to cool. The force of the demolding can reach high values [7]. At the time of demolding of the foam pieces, it is necessary that the mold surface manifests a low superficial energy [8] and has a favorable texture [9]. Furthermore, the creation of a mechanical barrier to avoid fixing [10], the prevention of spreading between the surfaces, and limitation of electrostatic attraction [11] are all required.

The polyurethane foam industry normally uses demolding agents in liquid form [12], which are applied to the mold surface in order to manufacture the polyurethane foam using the reaction technique [13]. These are usually aqueous dispersions with amine accelerators, foam stabilizers with 
siloxanes, polyethylene waxes, and polybutadienes. The reduction or elimination of the demolding agents is of interest to these industries because of the high consumption and cost of these products. The application of non-stick coatings could provide a substantial improvement to solving the problem.

Non-stick coatings are used in many applications of industrial molding. Studies have been made of applications with coatings of fluoropolymers, as described in [14-16], of sol-gel type, as shown in [17], and of silicon rubber, as in [18], among others. Studies have examined the behavior of PUR foam in aluminum molds with commercial coatings of polytetrafluoroethylene (PTFE), perfluoroalkoxy (PFA), and fluorinated ethylene propylene (FEP), as described in $[19,20]$. Nevertheless, the authors have not found previous works centered on the use of other non-stick coatings for PUR molds, such as ceramic coatings or RTV1 (silicone rubber)-type elastomer coatings.

The main aims of this study are to identify and evaluate different non-stick coatings applied to aluminium molds in order to manufacture PUR foam without the necessity of a demolding agent. The coatings studied were: TFI 851 E (PTFE), TF-76521 (PFA), TFI-3531 (FEP), TFC-51 N (sol-gel type), TS-RTV1 silicone rubber without cerium, and TS-RTV1 doped with cerium. These coatings could be especially useful for PUR foam release applications because they have characteristics such as: low surface energy, hydrophobicity, excellent anti-adhesion properties, high chemical resistance, good mechanical properties, and high temperature stability [21-25].

To study the behavior of the coatings, traditional techniques (roughness measurement, sliding angle measurement) were used. Also, a recently patented test of release force of PUR foam and a new method focused on the behavior of the coatings on the front of one of the foam components were employed [26]. Finally, industrial tests were performed to verify the results of laboratory. These tests are considered the second important contribution of the study.

The structure of this paper is as follows: Section 2 describes the equipment and material used; Section 3 shows the results, which are thereafter discussed in Section 4; finally, the conclusions are expressed in Section 5.

\section{Materials and Methods}

\subsection{The Foam Mold}

The diisocyanate of $4,4^{\prime}$ methylene diphenyl diisocyanate (MDI) and polyol used in the manufacturing of polyurethane foam was supplied by Grupo Copo Company (Vigo, Spain), which is a company that specializes in the development and manufacturing of alveolar polymers in the automobile field. The foam was obtained from mixing polyol formed with MDI with a weight relation of 100/57.7 (polyol/MDI). The foams were obtained in an enclosed mold, resulting in a density between 64 and $66 \mathrm{~kg} / \mathrm{m}^{3}$.

The process of obtaining the foam was to pour a measured quantity in weight of polyol over a quantity of MDI and mix vigorously with a mixer $(1000 \mathrm{rpm})$ for $10 \mathrm{~s}$. Immediately afterwards, without pause, the dilution was poured into the molds in a uniform manner. The molds were preheated to a temperature of $50-60^{\circ} \mathrm{C}$, after which the poured combination of polyol and MDI was put in an oven at $60{ }^{\circ} \mathrm{C}$ for a period of $5-7 \mathrm{~min}$. The foam formed and grew. The mold was sealed with lids.

To study the release force of the polyurethane foam, a rectangular mold was made with removable lids: one for the base and one for the top. Added to this was an intermediate plate with four window cutouts. These windows allowed rectangular samples to be taken, with one side being non-stick coated. The flat specimens came out in such a way that the uncoated side faced outward, without having been in contact with the foam which is formed inside the mold. The mold is shown in Figure 1. 


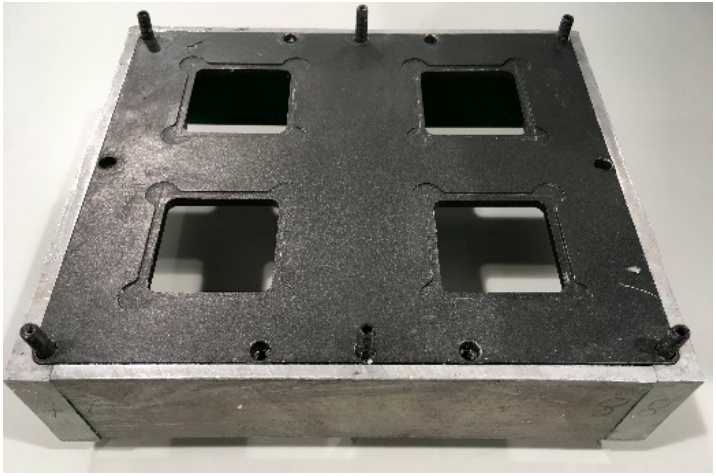

(a)

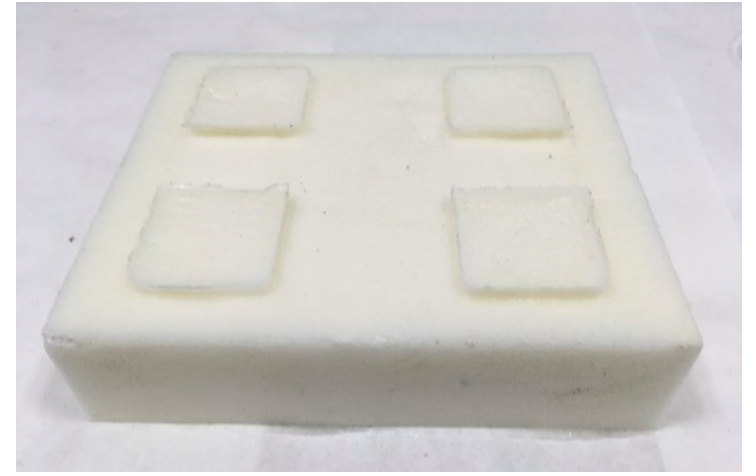

(b)

Figure 1. Rectangular mold for the manufacturing of polyurethane (PUR) foam: (a) frame of the mold with four window plates to insert flat non-stick specimens; (b) piece of PUR foam obtained.

The walls of the molds are made from mechanized cast-aluminium EN AC 42100 and their internal dimensions are $197 \times 165 \times 48 \mathrm{~mm}^{3}$. The windows permit the insertion of flat specimens of $49 \times 49 \times$ $1.2 \mathrm{~mm}^{3}$ of aluminium EN AW 5754, one of whose sides is non-stick coated, thus leaving a surface of $45 \times 45 \mathrm{~mm}^{2}$ in actual contact with the foam. This allows one to determine the release force of the foam on the coating after various cycles.

Twenty cycles were carried out. Each cycle of foam studied entailed the following: (a) the mounting of the frame; (b) formation of the PUR foam in the mold; (c) after 20 min of curing, release with dynamometric equipment and determination of the release force of the non-stick coated plates with PUR foam; (d) demolding of the PUR foam from the mold; and (e) cleaning of the mold and preparation for the next cycle. An axial force testing machine IMADA MX2 $500 \mathrm{~N}$ with $100 \mathrm{~N}$ dynamometer (Imada Co., Ltd., Toyohashi, Japan) was used in the tests.

\subsection{The Coatings}

The coatings were selected for their toughness and applicability to industry, and due to previous experience using the applicator TECNIMACOR (Cordoba, Spain). Six coatings were studied with this method and four specimens were taken from each coating. The molds were made identically.

The coatings studied were (Figure 2):

- $\quad$ TFI $851 \mathrm{E}$ is a coating made with PTFE, whose recommended use is for multi-layered antiadherents applied to demolding in engineering, the food industry, and the metal-mechanical industry in general.

- $\quad$ TF-76521 is a fluoropolymer based on PFA, among whose common uses are: trays and molds for bakery and related industries, and in solutions for engineering in general.

- TFI-3531 is a fluoropolymer based on FEP, and among its uses are: molds for thermoforming, molds for thermofusion, hoppers for doughs in the food industry, etc.

- $\quad$ TFC-51 N is a non-stick coating of the sol-gel type; it is used in kitchen utensils and renowned for its resistance to wear and toughness.

- Finally, TS-RTV1 is a silicon rubber elastomeric coating that polymerizes in the air and is typically used in the bakery industry. Tests were carried out with the elastomers without doping and doped with nanoparticles, such as those proposed in the literature [27].

The coatings were characterized by means of determining their thickness and pencil hardness resistance. The layer thickness was measured by Leptoskop 2024 of Karl Deutsche measuring equipment (KARL DEUTSCH Prüf- und Messgerätebau GmbH + Co KG, Wuppertal, Germany), with a resolution of $0.1 \mu \mathrm{m}$ under the ISO 2808 standard [28] and the scratch resistance test according 
to ISO 15184 [29]. For the determination of color, a RAL color normalized table (RAL gemeinnützige $\mathrm{GmbH}$, Bonn, Germany) of 1625 colors was used [30].

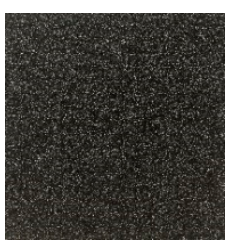

(a)

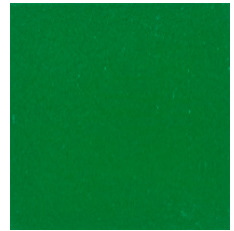

(b)

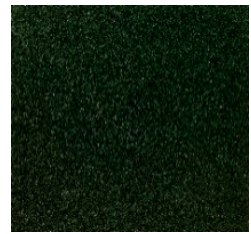

(c)

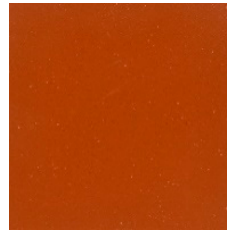

(d)

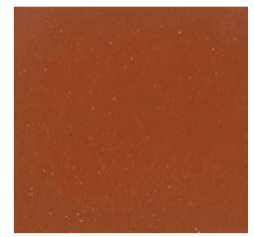

(e)

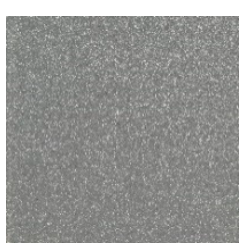

$(\mathbf{f})$

Figure 2. Tested coatings: (a) TFI-76521 (perfluoroalkoxy (PFA)); (b) TF-531 (fluorinated ethylene propylene (FEP)); (c) TFI-851E (polytetrafluoroethylene (PTFE)); (d) TS-RTV1 (silicone rubber); (e) RTV1 + Ce (silicone rubber +cerium); and (f) TFC-51N (sol-gel. Ceramic).

\subsection{Laboratory Tests}

The surface roughness of the antiadherent was evaluated after each cycle of release. For measuring the surface roughness, a Mitutoyo SJ-201 measuring device (Mitutoyo Corporation, Sakado, Japan) was used and the parameters $R_{\mathrm{a}}, R_{\mathrm{z}}$, and $R_{\mathrm{q}}$ were measured.

The sliding angle was measured as an indicator of the non-stick capacity of the coatings of the test plates after each foam cycle [31]. To determine this, a device was used equipped with a tilting plate, which was able to tilt to a degree of $10^{\circ} / \mathrm{min}$ and which also enabled a specific volume of water to be dropped onto the coated surfaces. The drops of water used to determine the angle measurement were demineralized and of $10^{\circ} / \mathrm{min}$, and they were deposited by means of an adjustable volume pipe. A digital inclinometer was used to measure up to a precision of $\left(0.05^{\circ}\right)$. The inclinometer is magnetic and can be placed on the edge of the tilting plate. The detection of the overall sliding of the drop was done visually. For each surface to be analyzed, three drops were deposited and analyzed.

The equipment used to obtain measurements for release force was the model MX2 $500 \mathrm{~N}$ manufactured by IMADA (Imada Co., Ltd, Toyohashi, Japan) with the incorporation of a dynamometer of $100 \mathrm{~N}$. The tests were carried out with a speed-displacement of $100 \mathrm{~mm} / \mathrm{min}$. This is the speed of release for each cycle of foam. Four figures were obtained, one for each specimen, on the release force of each cycle of the foaming.

In order to determine the release force of the PUR foam on the specimens of aluminium with non-stick coating, bonded with cyanoacrylate glue was a steel sheet of $35 \times 35 \mathrm{~mm}^{2}$ on the side that was not covered by the samples of Al-Mg. On this steel sheet, a magnetized part was fixed by incorporating it with a screwed nut with a cylindrical section, on which the hook was screwed to enable fixing it to the test bench with a dynamometer (Figure 3).

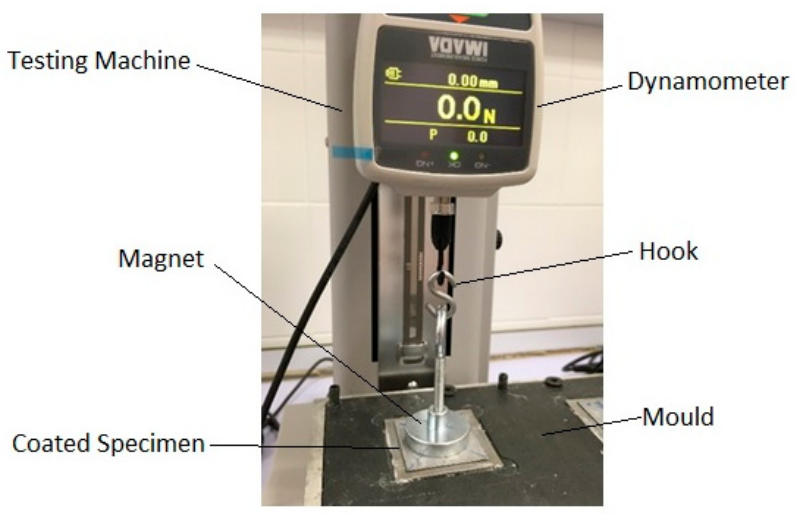

Figure 3. Setup to determine the release force in the coated specimens of $45 \times 45 \mathrm{~mm}^{2}$. 


\subsection{Laboratory Tests with MDI}

The influence of the coated surfaces after prolonged contact with MDI was studied. It is known that the MDI, one of the reagents of PUR foam, produces a penetrating effect on the coatings [19]. For this, a vial of $10 \mathrm{~mL}$ capacity was used, into which was poured $5 \mathrm{~mL}$ of MDI. Then, the vial was placed facedown with the mouth leaning on the coating, firmly held by sticky tape, and placed in an oven at $60{ }^{\circ} \mathrm{C}$ for variable times, from 24 to $120 \mathrm{~h}$.

Once done, the roughness $R_{\mathrm{a}}$ and the release force of the PUR foam was determined. In addition, an analysis was made by means of a Quanta 400 model sweeping electronic microscope (Thermo Fisher Scientific, Hillsboro, OR, USA) of the surface conditions of the coatings, which were then mapped with the spectroscopy technique of energy dispersive of X-rays (EDX).

\subsection{Tests in the Industry}

Finally, a test was carried out in real surroundings with the two best-behaved coatings from the laboratory tests. The coatings were applied in molds supplied by the Copo Iberica S.A. Company (Vigo, Spain) at the TECNIMACOR facilities. The field tests were carried out at CETEC (Technological Centre of Grupo Copo).

The same stages and operations were performed as with any mold production (preparation, adjustments and carousel placing, adjustments to casting parameters, and system servicing).

The requirement is that the piece be taken out easily from the mold without any type of tearing of the polyurethane and without resistance to the demolding operation.

The mold was tested in a circular carousel of HR (high resilience) polyurethane foaming with an automated PUR injection system.

\section{Results}

\subsection{The Coatings}

The data on coatings (thickness, scratch resistance, and color) are shown in Table 1. They are in agreement with the characteristics expected, as described in [32] for fluoropolymers or in [33] for ceramic materials.

Table 1. Non-stick coatings on aluminum plates used in cycles of forming of PUR foam.

\begin{tabular}{cccccc}
\hline Type of Coating & Type & Thickness $(\boldsymbol{\mu m})$ & Pencil Hardness & Color & RAL \\
\hline TFI-851 E & PTFE & $35 \pm 5$ & 2H-H & Pearl green & 1404030 \\
TF-76521 & PFA & $55 \pm 10$ & H-F & Black/green & $0001500 / 1304030$ \\
TF-3531 & FEP & $50 \pm 5$ & H & Green & 1504040 \\
TFC-51 N & Sol-gel. Ceramic & $45 \pm 7$ & $4 \mathrm{H}-3 \mathrm{H}$ & Gray & 2405005 \\
TS-RTV1 & Silicon rubber & $65 \pm 8$ & B-2B & Orange & 0404050 \\
TS-RTV1 + Ce & Silicon rubber & $62 \pm 10$ & B-2B & Orange & 0404050 \\
\hline
\end{tabular}

\subsection{Laboratory Tests without MDI}

The behavior of the different coatings in the laboratory tests was studied, thus determining the critical sliding angle, roughness, and release force after each foam cycle of the proposed specimens. Twenty consecutive cycles were carried out for each set of coated specimens. The results are shown in the illustrations accompanying Figures 4-7. 


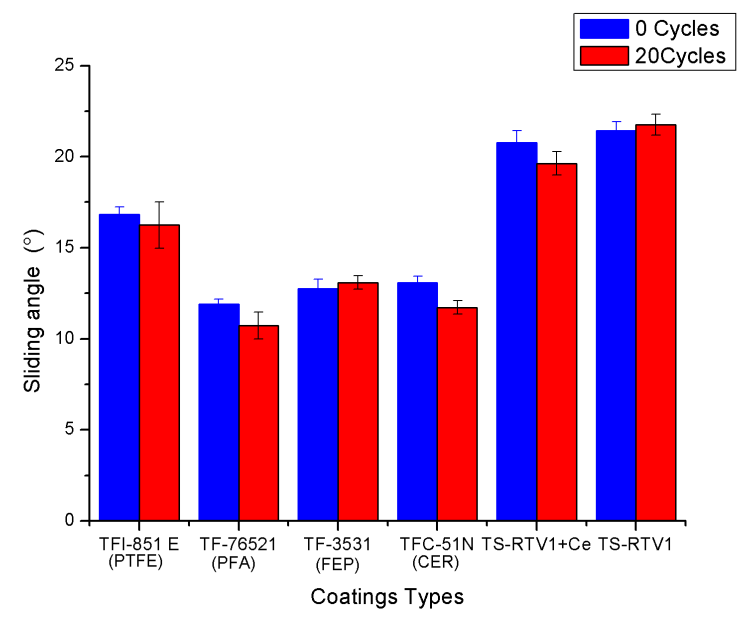

Figure 4. Critical sliding angle $\left(^{\circ}\right)$ of the coatings studied. Initial state and after 20 cycles.

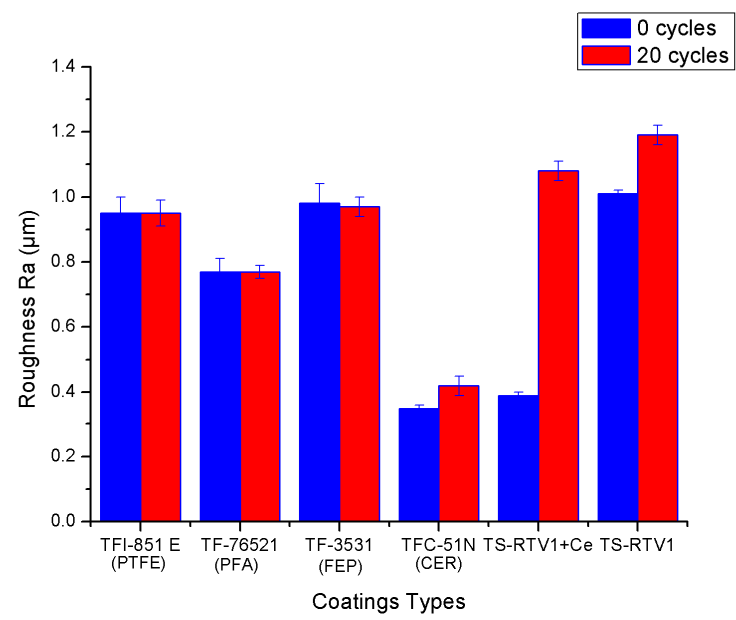

Figure 5. Roughness $R_{\mathrm{a}}(\mu \mathrm{m})$ of the coatings studied. Initial state and after 20 cycles.

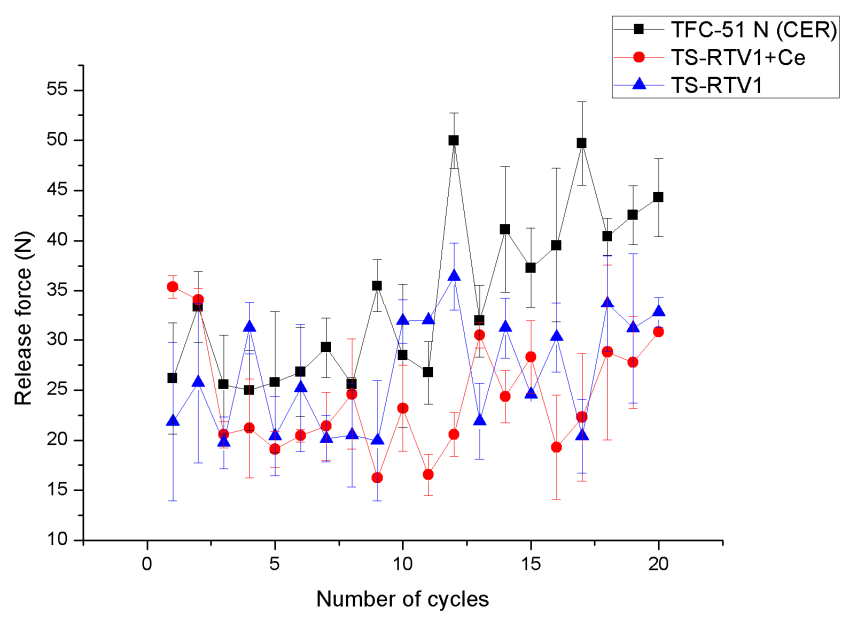

Figure 6. Release force of PUR foam on a flat surface of $45 \times 45 \mathrm{~mm}^{2}$ as a function of the foam cycles analyzed. Non-fluoropolymer coatings. 


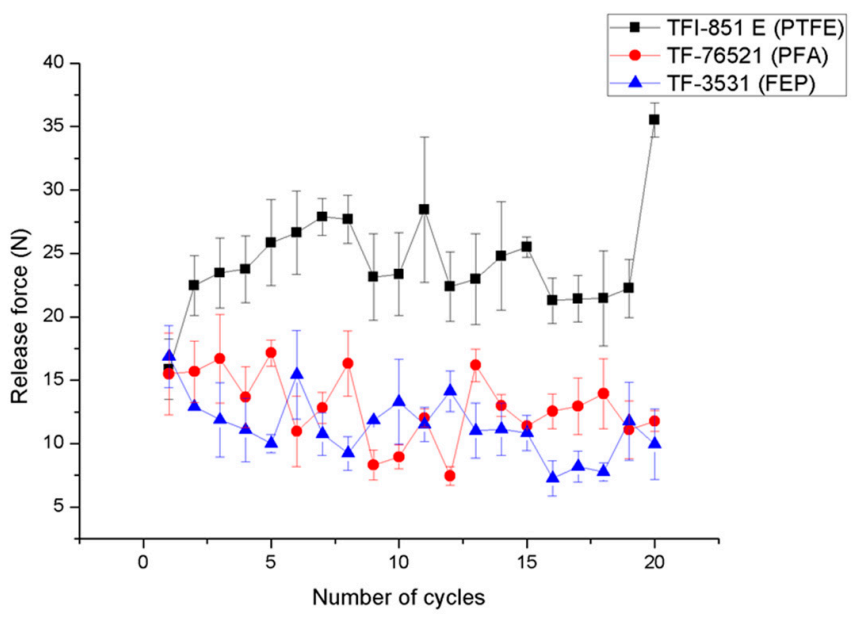

Figure 7. Release force of PUR foam on a flat surface of $45 \times 45 \mathrm{~mm}^{2}$ as a function of the foam cycles analyzed. Fluoropolymer coatings.

\subsection{Laboratory Tests with MDI}

The lowest values of the release force of the PUR foam were obtained with the fluoropolymer coatings of FEP and PFA. For both, after contact with the MDI reagent, the roughness $\left(R_{\mathrm{a}}\right)$, the sliding angle, and the release force of the PUR foam (Table 2) were determined.

Table 2. Roughness $R_{\mathrm{a}}(\mu \mathrm{m})$, sliding angle $\left(^{\circ}\right)$, and release force of PUR foam $(\mathrm{N})$ on of the FEP and PFA coatings studied. After $24 \mathrm{~h}$ and $120 \mathrm{~h}$.

\begin{tabular}{cccc}
\hline Type of Coating and Contact Time with MDI & $\boldsymbol{R}_{\mathbf{a}}(\boldsymbol{\mu m})$ & Sliding Angle $\left(^{\circ}\right)$ & Release Force $(\mathbf{N})$ \\
\hline TF-3531 (FEP) $24 \mathrm{~h}$ & $1.3 \pm 0.3$ & $21.0 \pm 2.0$ & $6.9 \pm 2.0$ \\
TF-3531 (FEP) $120 \mathrm{~h}$ & $1.1 \pm 0.1$ & $33.0 \pm 3.5$ & $7.3 \pm 1.5$ \\
TF-76521 (PFA) 24 h & $1.3 \pm 0.4$ & $25.0 \pm 2.0$ & $7.0 \pm 1.0$ \\
TF-76521 (PFA) $120 \mathrm{~h}$ & $0.9 \pm 0.1$ & $40.0 \pm 2.0$ & $7.0 \pm 1.5$ \\
\hline
\end{tabular}

SEM (scanning electron microscope) images of the PFA and FEP coatings (Figure 8) were taken in their initial state and after $24 \mathrm{~h}$ and $120 \mathrm{~h}$ of contact with MDI.

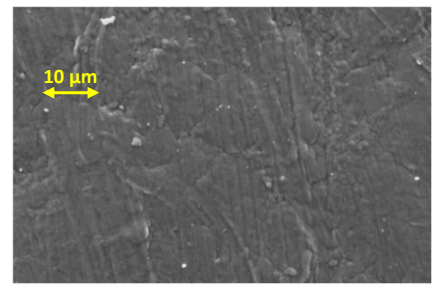

(a)

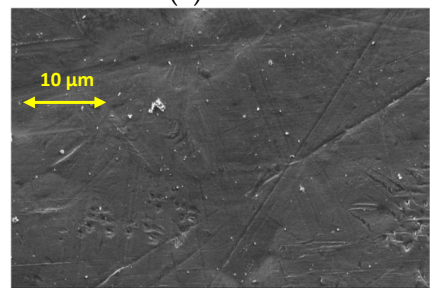

(d)

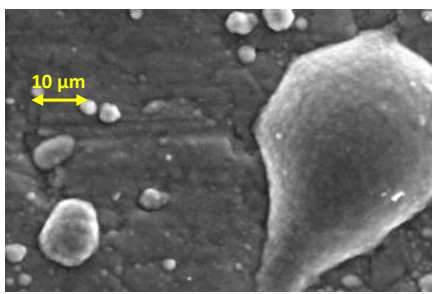

(b)

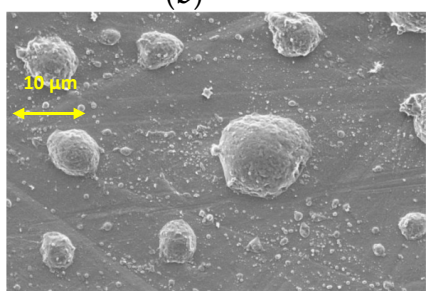

(e)

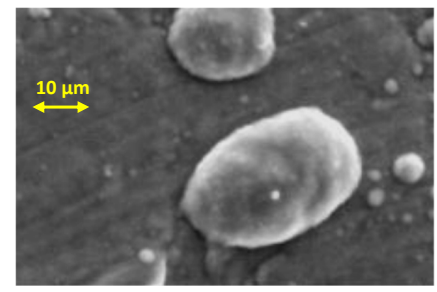

(c)

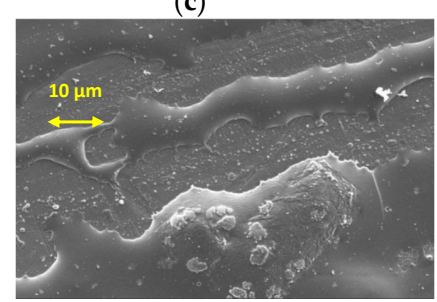

(f)

Figure 8. Images obtained by SEM, after contact with 4,4'methylene diphenyl diisocyanate (MDI), of TF-3635 (FEP): (a) reception; (b) after $24 \mathrm{~h}$; and (c) after $120 \mathrm{~h}$, and of TF-76521 (PFA): (d) reception; (e) after $24 \mathrm{~h}$; and (f) after $120 \mathrm{~h}$. 
Along with the morphology obtained by SEM, an EDX analysis was performed. Due to their chemical composition, the elements that allow identification of the coatings of FEP, PFA, and MDI are fluorine and nitrogen, respectively (Figure 9).

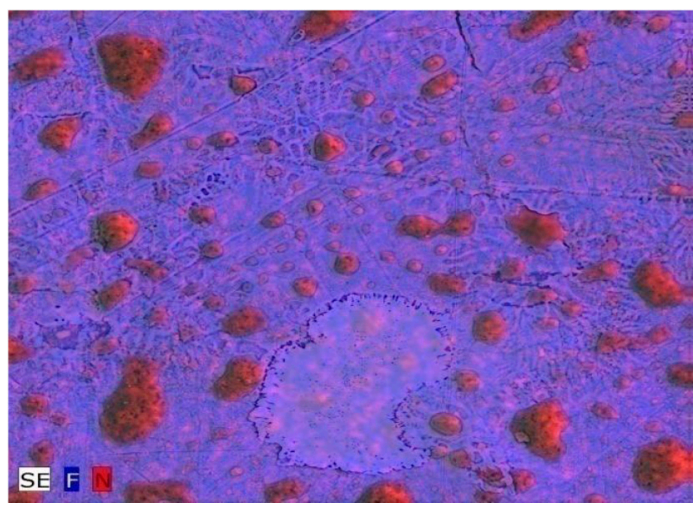

Figure 9. EDX mapping with fluorine (blue) and nitrogen (red) labeling in PFA specimens attacked with MDI for $120 \mathrm{~h}$.

\subsection{Tests in the Industry}

Finally, field tests were taken with pieces of factory-produced PUR foam. The industrial test results are shown in Table 3.

Table 3. Results of the industrial test of pieces of PUR foam in a mold of aluminium with two tracks, so that in one, the FEP-type coating was applied, and in the other, PFA was applied.

\begin{tabular}{|c|c|c|c|}
\hline Day & $\begin{array}{c}\text { No. Pieces (No. } \\
\text { Pieces Accumulated) }\end{array}$ & TF-3531 (FEP) & TF-76521 (PFA) \\
\hline 1 & 206 & Local adherence $^{2}$ & Without incidences ${ }^{1}$ \\
\hline 2 & $290(496)$ & Some adherence, slight cleaning ${ }^{3}$ & Without incidences ${ }^{1}$ \\
\hline 3 & $250(746)$ & $\begin{array}{c}\text { Adherence, slight cleaning, demolding } \\
\text { in vents } 4\end{array}$ & Without incidences ${ }^{1}$ \\
\hline 4 & $208(954)$ & $\begin{array}{l}\text { Adherence, slight cleaning, demolding } \\
\text { in vents }{ }^{4} \text {, and } 10 \text { units discarded }{ }^{5}\end{array}$ & Without incidences ${ }^{1}$ \\
\hline 5 & $183(1137)$ & $\begin{array}{l}\text { Adherence, slight cleaning, demolding } \\
\text { in vents } 4 \text {, and } 13 \text { units discarded }{ }^{5}\end{array}$ & Local adherence $^{2}$ \\
\hline 6 & $178(1315)$ & $\begin{array}{l}\text { Adherence, slight cleaning, demolding } \\
\text { in vents }{ }^{4} \text {, and } 16 \text { units discarded }{ }^{5} \text {. } \\
\text { Stopped for cleaning } 6\end{array}$ & Local adherence $^{2}$ \\
\hline 7 & $153(1468)$ & $\begin{array}{l}\text { Adherence, slight cleaning, demolding } \\
\text { in vents }{ }^{4}, \text { and } 16 \text { units discarded }{ }^{5} \\
\text { Increase in } \mathrm{n}^{\circ} \text { of stops for cleaning }{ }^{6}\end{array}$ & Local adherence $^{2}$ \\
\hline 8 & - & $\begin{array}{l}\text { Start of use of demolding } \\
\text { (1 out of every } 2 \text { foamings) }\end{array}$ & $\begin{array}{l}\text { Start of use of demolding } \\
\text { (1 out of every } 4 \text { foamings) }\end{array}$ \\
\hline \multicolumn{4}{|c|}{$\begin{array}{l}{ }^{1} \text { Without incidences: correct piece, without PUR adherences; }{ }^{2} \text { local adherence: correct part, but with local PUR } \\
\text { adherences in the mold; }{ }^{3} \text { some adherence, slight cleaning: correct piece, but with partial PUR adherence that needs } \\
\text { minor cleaning operations; }{ }^{4} \text { adherence, slight cleaning, demolding in vents: correct piece, but with PUR adherences } \\
\text { that demand the use of demolding in complex zones, such as vents; }{ }^{5} \text { units discarded: the demolding operation has } \\
\text { produced breakage of the foam and the piece is discarded; }{ }^{6} \text { stops for cleaning: the parts manufacturing carousel } \\
\text { must be stopped and mold cleaning is more intensive due to permanent adhesion of PUR foam. }\end{array}$} \\
\hline
\end{tabular}

\section{Discussion}

In the present work, the behavior of different coatings in the processes of demolding of PUR foam was studied; a total of six different coatings undergoing 20 demolding cycles were examined. 
After each cycle, each coating was characterized by means of the sliding angle, surface roughness, and release force. The coatings with the best behavior then underwent an additional laboratory test, with MDI in the molds, on an industrial scale.

In relation to the critical sliding angle (Figure 4), it is necessary to indicate:

- The highest values were obtained with elastomer coatings of silicon rubber TS-RTV1 $\left(20^{\circ}-22^{\circ}\right)$. These values are compatible with those found in the literature [34].

- There seems to be no difference between the values of the non-stick application of silicon rubber with or without cerium. Previous studies reported lower values for RTV1 + Ce and better behavior in the case of contact with water or ice [24]. These phenomena were not identified for PUR foam.

- The lowest values of the sliding angle were obtained with TF-5621 coatings of PFA base $\left(11^{\circ}-13^{\circ}\right)$, TF-3531 with FEP base $\left(12^{\circ}-13^{\circ}\right)$, and the sol-gel, ceramic, TFC-51 N $\left(13^{\circ}-14^{\circ}\right)$.

Regarding the roughness of the coatings (Figure 5):

- The lowest values were obtained with the TFC-51 N ceramic coating $(0.3-0.5 \mu \mathrm{m})$. This is not related to low values for release force of PUR foam. Similar conclusions were reached in the case of foodstuff demolding (pancake) on metallic surfaces for sol-gel coatings [33].

- The RTV1 coatings without cerium, those doped with cerium, and those of PTFE/TFI-851 E base obtained $R_{\mathrm{a}}$ values oscillating between 0.9 and $1.2 \mu \mathrm{m}$, the highest.

- The coatings with resins rich in PFA and FEP gave intermediate values between 0.7 and $1.0 \mu \mathrm{m}$, the FEP type roughness values being slightly higher than the PFA ones. In the case of fluoropolymer coatings, the roughness appears to show the opposite effect to the sol-gel (ceramic) coatings. The lowest values for roughness, among others, coincided with lower values for release of PUR foam. This was studied in [35].

In relation to the release force (Figures 6 and 7), in the 20 cycles carried out, it must be pointed out that:

- The lowest results were obtained with the TF-3531 (FEP) and TF-76521 (PFA) coatings. The values obtained varied between 5 and $20 \mathrm{~N}$. These results coincide with those observed by Figueiredo et al. [19] and Akinci and Cobanoglu [20].

- The silicon rubber, the ceramic type, and PTFE re-coverings seem to show a more unstable behavior and obtained release force values varying between 20 and $50 \mathrm{~N}$.

- The results indicate that the critical sliding angle may be a good indicator for the selection of coating, since the lowest sliding angle coincides with the coating with less release force, as was also observed in [20].

From the results of thickness and pencil hardness (Table 1; Figures 6 and 7), it can be said that:

- The coatings with better behavior presented similar thicknesses and surface hardness: PFA produced $55 \pm 10 \mu \mathrm{m}$ and an H-F hardness; FEP had $50 \pm 5 \mu \mathrm{m}$ and an F hardness.

- There is no relationship between the thickness or hardness of the coating and the demolding behavior of the PUR foam. The harder coatings (TFC-51 N) or thicker coatings (TS-RTV1 or TS-RTV1 + Ce) that were tested had poor performances in the release force tests.

From the results obtained after the tests with MDI, the following points can be affirmed:

- The images FEP and PFA coatings contacted with MDI show a significant change after exposure (Figures 8 and 9). These results coincide with the literature in the case of PFA [19].

- Initially, a compact fibrillar structure was observed in the control specimens (a) and (d), even without contact with MDI. After exposure and after 24 and $120 \mathrm{~h}$, the surface acquired a grainy texture. It can be seen that the grains of the FEP coatings are bigger than those of PFA. Taking into account that the grains are produced with the MDI attack, (Figure 8), we can 
infer that the attack is more severe in the FEP coatings than those of PFA, just as observed by Figueiredo et al. [19].

- Furthermore, the sliding angle increased significantly after the attack, although less so in the PFA than the FEP, as seen in [20], but not the release force, which was almost unalterable. This occurred in a similar way with both coatings.

After the industrial test, it can be pointed out that:

- The expectations of the laboratory test were confirmed, and the best results were obtained with the TF-76521 (PFA) coating, which seems to allow the manufacturing of some 1500 pieces without using any type of demolding and practically without incidences.

- For the TF 3531 (FEP) coating, some incidences began, initially slight, but then greater, after about 500 pieces. Both experimental results on an industrial scale confirm the idea proposed by Figueiredo et al. [19] and Akinci and Cobanoglu [20].

Finally, the follow affirmations can be stated after the present study:

- The critical sliding angle can be a good indicator for the selection of a coating for molds for manufacturing of PUR pieces, since the lower sliding angle values are associated with lower release force values.

- The topography generated by the FEP and PFA coatings seems to have a certain similarity with the hydrophobic effects associated with the "lotus leaf" phenomenon [36], creating structures that allow trapping a certain level of air in the rough surfaces [37]. Therefore, fluorinated coatings with $R_{\mathrm{a}}$ roughness levels in the range of $0.8-1 \mu \mathrm{m}$ have a better response than coatings with less roughness. PTFE coatings are also highly fluorinated coatings with $R_{\mathrm{a}}$ values similar to FEP and PFA but, in this case, their porous structure seems to produce foam interlocking effects that significantly increase the release force of the PUR foam.

- On the other hand, the study of the contact with isocyanate shows us that the isocyanate percolates through the hollows of the surface and wears out the upper part of it. Small areas of the surface where the MDI adheres begin to appear, eventually forming films of this compound that clog the polymer. This phenomenon is more intense in FEP coatings than in PFA coatings. This effect can also be responsible for the increase in the adhesion measured, because if the surface of a chemically very hydrophobic material is covered with another less hydrophobic one, the non-stick capacity must necessarily be lost.

\section{Conclusions}

A study was carried out on the most important non-stick coatings, according to their typical use in engineering, to address adhesion problems in aluminium pieces. Coatings were selected that are representative of the most-used typologies: elastomers (silicone rubber), ceramics (sol-gel), and fluoropolymers.

A procedure was designed to manufacture PUR foam and to determine the adhesion force in aluminium specimens coated in different materials. A laboratory test was carried out identifying the coatings with the best behavior in the demolding of PUR foam. The idealness of these selected coatings was confirmed in field tests.

Ultimately, for the manufacturing of PUR foam, the aluminium molds-which contained non-stick coatings on their walls-have the following behavior:

- The molds coated with RTV elastomer with and without cerium, and molds with PTFE coating, are not apt for PUR foam demolding. Although the values of maximum release force, roughness, and sliding angle remain relatively stable with an increasing number of cycles, the values of release force are high, around 2-2.5 times those of the FEP and PFA type. On an industrial scale, this will result in difficulty in demolding and incidences in production. 
- The molds coated in ceramic of the sol-gel type are unadvisable for the manufacturing of PUR foam because, although the sliding angle values obtained are average and of low roughness, the release force is high and undergoes a notable increase when the number of cycles increases, up to 3 times the values of FEP and PFA coatings.

- The molds coated with PFA- and FEP-type fluoropolymers are the most apt for manufacturing PUR foam. They undergo no significant variation in sliding angle, roughness, and release force values. They possess the lowest values of release force and sliding angle, although their roughness values are relatively high.

- Between the two fluoropolymer coatings with the better responses, it has been determined that FEP coatings suffer from an isocyanate (MDI) condition of a greater magnitude than PFA coatings.

- In an industrial application, it was possible to manufacture around 1500 units of PUR foam in aluminium molds with a PFA-type coating, and around 500 units with FEP, without incidences. From then on, the coated molds needed demolding to some degree: in the case of PFA, 1 out of every 4 foamings; for FEP, 1 out of every 2.

- The PFA fluoropolymer coatings allowed the obtaining of a significant amount of PUR foam pieces without any type of demolding. When the coating began to wear out, it was still useful, with a significant saving in demolding.

Author Contributions: Conceptualization, G.G.-V., M.C.-V. and M.A.R.-V.; Methodology, All authors; Validation, G.G.-V., M.A.R.-V., P.E.R. and O.R.-A.; Formal Analysis, G.G.-V., P.E.R., M.A.R.-V. and O.R.-A.; Investigation, F.S.-U. and G.P.-G.; Resources, G.G.-V., and M.A.R.-V.; Data Curation, G.G.-V., M.C.-V. and M.A.R.-V.; Writing-Original Draft Preparation, G.G.-V., P.E.R., M.A.R.-V. and O.R.-A., Writing-Review \& Editing, G.G.-V., P.E.R., M.A.R.-V., F.S.-U. and O.R.-A.; Visualization, All authors; Supervision, G.G.-V., and M.A.R.-V.; Project Administration, G.G.-V., and M.A.R.-V.

Funding: This study was funded by the European Fund for Regional Development, the Ministry of Economy and Competitiveness of the Government of Spain and the Centre for Industrial Technological Development (CDTI) ( $\mathrm{n}^{\mathrm{o}}$ ITC-2015237), as well as by Project for Excellence Andalusian Research Plan (P12-FQM-1443).

Acknowledgments: The authors wish to thank Grupo Copo and especially CETEC (Technological Centre of Grupo Copo) for facilitating the means to be able to carry out the field tests. Special gratitude is shown to Arturo Gallego of the COPO group and Alfonso Vázquez of the AIMEN association (Association of Metallurgic Research of the Northwest) for his useful advice.

Conflicts of Interest: The authors declare no conflict of interest. The funders had no role in the design of the study; in the collection, analyses, or interpretation of data; in the writing of the manuscript, and in the decision to publish the results.

\section{References}

1. Landrock, A.H. Handbook of Plastic Foams: Types, Properties, Manufacture, and Applications; William Andrew: New York, NY, USA, 1995.

2. Meier-Westhues, U. Polyurethanes: Coatings, Adhesives and Sealants; European Coatings Tech Files; Vincentz Network: Hanover, Germany, 2007; ISBN 9783878703341.

3. Khemani, K.C. Polymeric foams: An overview. In Polymeric Foams: Science and Technology; American Chemical Society: Washington, DC, USA, 1997; Volume 669, pp. 1-7.

4. Casati, F.M.; Herrington, R.M.; Broos, R.; Miyazaki, Y. Tailoring the performance of molded flexible polyurethane foams for car seats. J. Cell. Plast. 1998, 34, 430-466. [CrossRef]

5. Krone, C.A.; Ely, J.T.A.; Klingner, T.; Rando, R.J. Isocyanates in flexible polyurethane foams. Bull. Environ. Contam. Toxicol. 2003, 70, 328-335. [CrossRef] [PubMed]

6. Wirpsza, Z.; Kemp, T.J. Polyurethanes: Chemistry, Technology, and Applications; Polymer Science and Technology Series; Ellis Horwood: Chichester, NY, USA, 1993; ISBN 9780136831860.

7. Zentay, P.; Zoller, Z.; Arz, G.; Vas, L.M. Model for the calculation of demoulding force for polyurethane parts. Period. Polytech. Mech. Eng. 1999, 43, 197-212.

8. Ganesh, V.A.; Raut, H.K.; Nair, A.S.; Ramakrishna, S. A review on self-cleaning coatings. J. Mater. Chem. 2011, 21, 16304-16322. [CrossRef] 
9. Navabpour, P.; Teer, D.G.; Hitt, D.J.; Gilbert, M. Evaluation of non-stick properties of magnetron-sputtered coatings for moulds used for the processing of polymers. Surf. Coat. Technol. 2006, 201, 3802-3809. [CrossRef]

10. Heilig, G.; Gross, T.; Steinberger, H. Non-Stick Coated Molds. U.S. Patent 6,887,420 B2, 3 May 2005.

11. Petrie, E.M. Abhesion-The science of non-stick surfaces. Met. Finish. 2012, 110, 28-31. [CrossRef]

12. Ashida, K. Polyurethane and Related Foams: Chemistry and Technology; CRC Press: Boca Raton, FL, USA, 2006; ISBN 9780203505991.

13. Solórzano, E.; Rodriguez-Perez, M.A. Polymeric foams. In Structural Materials and Processes in Transportation; Lehmhus, D., Busse, M., Herrmann, A.S., Kayvantash, K., Eds.; Wiley-VCH Verlag GmbH \& Co. KGaA: Wayne Heim, Germany, 2013; pp. 375-413; ISBN 9783527327874.

14. Guerrero-Vacas, G. Comparative Analysis of The Removal Processes of Fluoropolymer Anti-Adherent Coatings on Metallic Surfaces between Laser and Pyrolytic Technologies. Ph.D. Thesis, University of Malaga, Malaga, Spain, April 2013.

15. Drobny, J.G. Technology of Fluoropolymers; CRC Press: Boca Raton, FL, USA, 2014; ISBN 9781420042672.

16. Ebnesajjad, S.; Khaladkar, P.R. Fluoropolymer Applications in the Chemical Processing Industries: The Definitive User's Guide and Handbook; Plastics Design Library; William Andrew: Norwich, NY, USA, 2017; ISBN 9780323461153.

17. Wu, L.; Nemeth, S. Non-stick and scratch resistant sol-gel coating for aluminum. MRS Proc. $2003,778$. [CrossRef]

18. Cherney, E.A. RTV Silicone-A high tech solution for a dirty insulator problem. IEEE Electr. Insul. Mag. 1995, 11, 8-14. [CrossRef]

19. Figueiredo, L.; Bandeira, P.; Mendes, A.; Bastos, M.M.S.M.; Magalhães, F.D. Use of fluoropolymer permanent release coatings for molded polyurethane foam production. J. Coat. Technol. Res. 2012, 9, 757-764. [CrossRef]

20. Akinci, A.; Cobanoglu, E. Coating of Al mould surfaces with polytetrafluoroethylene (PTFE), fluorinated ethylene propylene (FEP), perfluoroalkoxy (PFA) and ethylene-tetrafluoroethylene (ETFE). e-Polymers 2009, 9, 033. [CrossRef]

21. Critchlow, G.W.; Litchfield, R.E.; Sutherland, I.; Grandy, D.B.; Wilson, S. A review and comparative study of release coatings for optimised abhesion in resin transfer moulding applications. Int. J. Adhes. Adhes. 2006, 26, 577-599. [CrossRef]

22. Scheirs, J. Fluoropolymers: Technology, Markets and Trends; Rapra Technology Limited: Shrewsbury, UK, 2001; ISBN 9781859572733.

23. Faust, W.D. Ceramic substrates for nonstick coatings. In 63rd Porcelain Enamel Institute Technical Forum; Ceramic Engineering and Science Proceedings; American Ceramic Society: Westerville, OH, USA, 2008; Volume 22, pp. 25-31.

24. Arianpour, F.; Farzaneh, M.; Kulinich, S.A. Hydrophobic and ice-retarding properties of doped silicone rubber coatings. Appl. Surf. Sci. 2013, 265, 546-552. [CrossRef]

25. Buskens, P.; Wouters, M.; Rentrop, C.; Vroon, Z. A brief review of environmentally benign antifouling and foul-release coatings for marine applications. J. Coat. Technol. Res. 2013, 10, 29-36. [CrossRef]

26. Guerrero-Vaca, G.; Rodriguez-Alabanda, O.; Romero, P.; Rodriguez-Valverde, M.; Cabrerizo-Vilchez, M. Máquina para Realizar Ensayos en PROBETAS cuya Superficie Tiene un Recubrimiento Antiadherente. Patent Application Number ES P201830700; Unpublished Work, Available online: https:/ / drive.google. com/open?id=1zcW-H2gB5n433XxvUJI7ga56WSWFnkJx (accessed on 25 August 2018).

27. Arianpour, F. Water and Ice-Repellent Properties of Nanocomposite Coatings BASED on Silicone Rubber. Master's Thesis, University of Quebec, Chicoutimi, QC, Canada, December 2010.

28. UNE-EN ISO 2808:2007 Paints and Varnishes-Determination of Film Thickness; International Standard Organization: Geneva, Switzerland, 2007.

29. ISO 15184:2012 Paints and Varnishes-Determination of Film Hardness by Pencil Test; International Standard Organization: Geneva, Switzerland, 2012.

30. RAL Colours. Available online: https://www.ral-farben.de/en/home/ (accessed on 25 August 2018).

31. Ruiz-Cabello, F.J.M.; Rodríguez-Valverde, M.A.; Cabrerizo-Vílchez, M. A new method for evaluating the most stable contact angle using tilting plate experiments. Soft Matter 2011, 7, 10457-10461. [CrossRef]

32. Thomas, P. The use of fluoropolymers for non-stick cooking utensils. Surf. Coat. Int. 1998, 81, $604-609$. [CrossRef] 
33. Ashokkumar, S.; Adler-Nissen, J. Evaluating non-stick properties of different surface materials for contact frying. J. Food Eng. 2011, 105, 537-544. [CrossRef]

34. Seyedmehdi, S.A.; Zhang, H.; Zhu, J. Superhydrophobic RTV silicone rubber insulator coatings. Appl. Surf. Sci. 2012, 258, 2972-2976. [CrossRef]

35. Majewski, C.E.; Hopkinson, N. Release characteristics of polymer surface when moulding polyurethane foam. Plast. Rubber Compos. 2007, 36, 438-444. [CrossRef]

36. Celia, E.; Darmanin, T.; Taffin de Givenchy, E.; Amigoni, S.; Guittard, F. Recent advances in designing superhydrophobic surfaces. J. Colloid Interface Sci. 2013, 402, 1-18. [CrossRef] [PubMed]

37. Kulinich, S.A.A.; Farzaneh, M. On wetting behavior of fluorocarbon coatings with various chemical and roughness characteristics. Vacuum 2005, 79, 255-264. [CrossRef]

(c) 2018 by the authors. Licensee MDPI, Basel, Switzerland. This article is an open access article distributed under the terms and conditions of the Creative Commons Attribution (CC BY) license (http:/ / creativecommons.org/licenses/by/4.0/). 